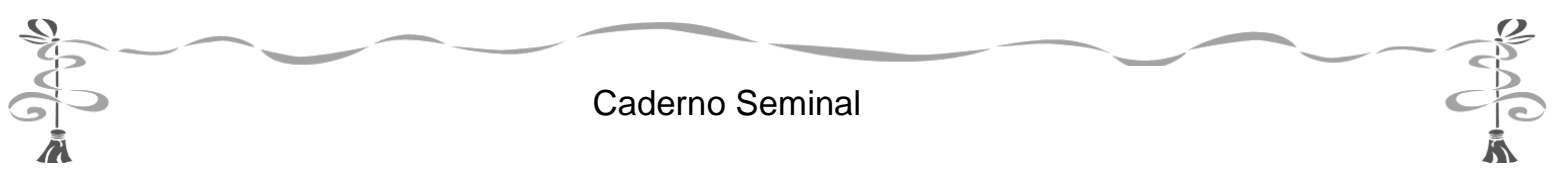

\title{
LITERATURA TIMORENSE: DA EMERGÊNCIA À LEGITIMAÇÃO ${ }^{73}$ EAST-TIMORESE LITERATURE: FROM EMERGENCY TO LEGITIMATION
}

Ana Margarida Ramos ${ }^{74}$

\section{RESUMO:}

Procedendo a uma caracterização breve da produção literária contemporânea de autoria timorense, com especial ênfase para a obra literária ficcional e poética, pretende-se refletir sobre as suas tendências e formas de afirmação. Autores como Luís Cardoso, no âmbito da ficção narrativa, ou de poetas como Fernando Sylvan, José Alexandre Gusmão, João Aparício, Jorge Barros Duarte, Jorge Lauten, Francisco Borja da Costa, Afonso Busa Metan, Crisódio T. Araújo, Celso Oliveira, Abé Barreto Soares, entre outros, exprimem bem a vitalidade crescente de uma literatura emergente, ainda muitas vezes próxima da referencialidade, procedendo à releitura e reescrita da História do país nas últimas décadas, a caminho do seu reconhecimento e necessária legitimação. Em termos práticos, será dada especial atenção à presença da literatura timorense em três contextos específicos, tendo em vista a sua institucionalização: crítica, a academia e os prémios. Para além de alguns estudos académicos mais ou menos pontuais e circunscritos, sua entrada recente no novo currículo do Ensino Secundário Geral de Timor-Leste, nomeadamente na disciplina de Temas de Literatura e Cultura oferecida aos alunos da Componente de Ciências Sociais e Humanidades, para além da presença mais pontual na disciplina de Português, afigura-se como um fator decisivo para a construção da identidade cultural e literária de um povo que também resistiu e combateu tendo por armas a pena e as letras.

PALAVRAS-CHAVE: Literatura Emergente; Literatura Timorense; Institucionalização e Legitimação.

\section{Abstract}

It's our purpose to make a brief characterization of contemporary East-timorese literature, with particular emphasis on literary fiction and poetry, in order to reflect on the process of recognition that is occurring in the last few years. Authors such as Luís Cardoso (fiction), or poets like Fernando Sylvan, José Alexandre Gusmão, João Aparício, Jorge Duarte Barros, Jorge Lauten, Francisco Borja da Costa, Afonso Busa Metan, Crisódio T. Araújo, Celso Oliveira, Abé Barreto Soares, among others, express the vitality of an emerging literature struggling for recognition and legitimacy. In practical terms, particular attention will be given to the presence of Timorese literature in three specific contexts: critical discourses, academia and prizes. In addition to some academic studies more or less specific and circumscribed, its recent entry in the new curriculum of Secondary Education in East Timor, particularly in the discipline of Themes of Literature and Culture, is analyzed as a decisive factor in the construction of cultural and literary east-timorese identity and literature.

KEYWORDS: Emerging literature; Timorese literature; institutionalization and legitimization

\footnotetext{
${ }^{73}$ Nota da editora: Manteve-se a grafia lusitana.

${ }^{74}$ Ana Margarida Ramos é doutorada em Literatura e professora auxiliar do Departamento de Línguas e Culturas da Universidade de Aveiro (Portugal). Tem desenvolvido investigação na área da Literatura para a infância e da promoção da leitura, na qual tem publicado diversos artigos em revistas e livros. É coautora do programa, manuais e guias da disciplina de Temas de Literatura e Cultura do curriculum do Ensino Secundário Geral em Timor-Leste. anamargarida@ua.pt
}

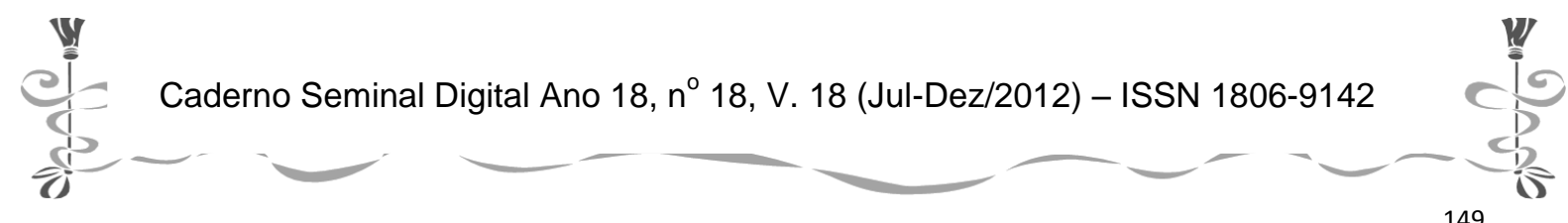




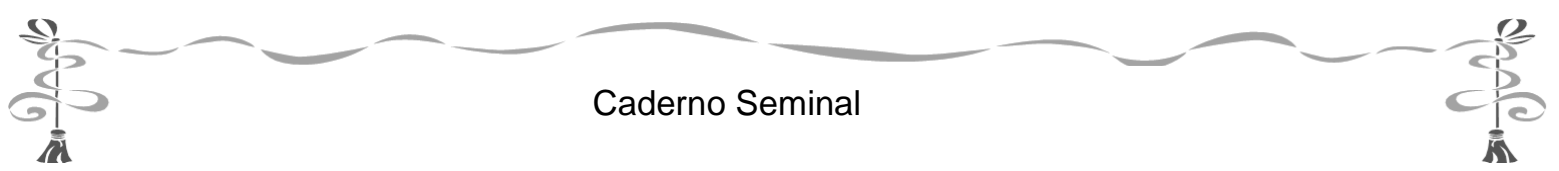

\section{Introdução}

As complexas questões de legitimação literária, decorrentes da combinação da ação de múltiplos fatores, alguns externos ao próprio texto e à sua validação estética, estão estreitamente relacionadas com o próprio conceito de cânone e de institucionalização do fenómeno literário, onde intervêm, por exemplo, a academia, a escola e o ensino e os prémios literários (Reis, 1997, p. 25-40). A formação do cânone, decorrente da ação combinada da seletividade (seleção de obras literária e culturalmente representativas da identidade), continuidade (permanência dos textos ao longo dos tempo, pluralidade e diversidade de leituras) e formatividade (perpetuação de valores, ideologias e estilos) (cf. Reis, 1997, p. 72-73), não é, atualmente, inibidora da afirmação de práticas literárias conotadas quer com a periferia do sistema literário, quer oriundas de contextos assumidamente minoritários e emergentes, como acontece com as recentes literaturas pós-coloniais ou com produções associadas a minorias sexuais e étnicas, por exemplo.

A defesa da gradual e progressiva abertura do cânone "sob a forma de revisão e abertura do cânone a textos representativos de saberes, classes e minorias tradicionalmente excluídos" (Duarte, s/d, s/p) surge como resultado da atual sociedade multicultural e da evolução de perspetivas de estudos que o percepcionam como "instrumento de repressão e discriminação ao serviço de interesses dominantes, do poder branco e masculino e de uma ideologia de contornos patriarcais, racistas e imperialistas" (idem).

Fátima Mendonça (2010) sublinha, para o caso moçambicano, a importância de um "reconhecimento" posterior e externo aferido pelos fatores que já enumeramos antes:

$\mathrm{Na}$ verdade, o desejo (consciente ou não) de nação vai sedimentando temas e formas discursivas, como parte de um novo sistema literário, mas a sua existência só é assegurada por um reconhecimento posterior pelos diversos elementos de recepção - crítica, reconhecimento nacional e internacional, prémios, edições nacionais e traduções - e que, integrados no sistema de ensino - curricula, programas, manuais reproduzem conceitos e valores que, atuando em cadeia, convergem para a instituição do novo cânone, a literatura nacional. (Mendonça, 2010, $\mathrm{s} / \mathrm{p})$

No caso em apreço, os últimos anos têm configurado um período de especial atenção para o universo da literatura timorense, quer em termos da academia e da crítica, com a realização de trabalhos de investigação e de publicações de índole científica sobre os textos, quer também do ensino, tanto ao nível universitário como secundário, como este estudo tentará mostrar.

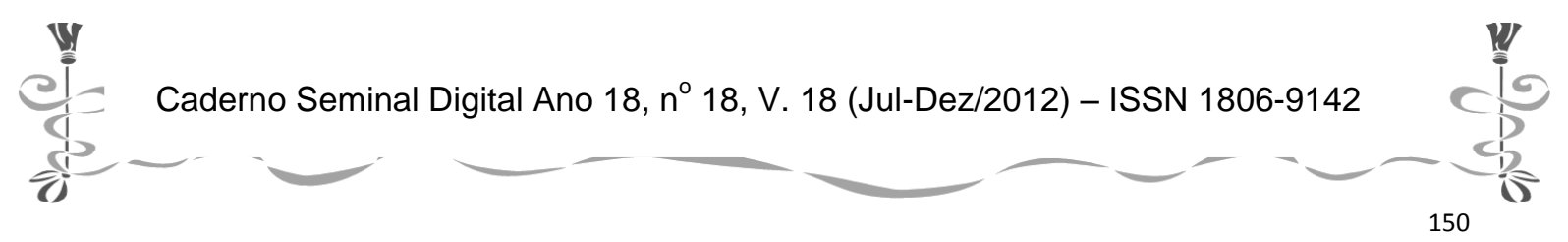




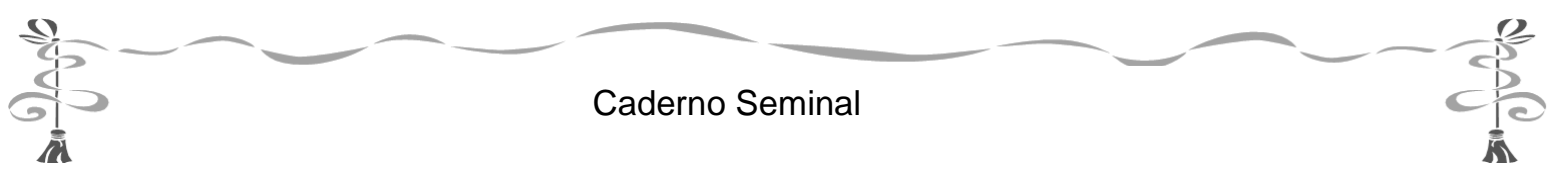

\section{Literatura Timorense - Retrato Atual}

À semelhança das outras literaturas que se revelaram após a independência dos respetivos países, como aconteceu, diferentemente, é certo, com os países africanos de língua oficial portuguesa, a literatura timorense vem fazendo, desde há décadas, um lento caminho de construção e afirmação, pesem embora as inúmeras vicissitudes do processo político e social e as suas repercussões de índole cultural e, mais especificamente, literária. No caso timorense, a diferença em relação aos países africanos acentua-se pelo facto de, face à ocupação indonésia, a língua - e consequentemente a literatura - ter desempenhado relevante função de resistência e de intervenção, sendo que a rutura com a herança e o paradigma português não se realizou de forma efetiva ou total. O conceito de emergência aqui utilizado decorre, pois, mais do processo de desenvolvimento e afirmação em que se encontra, do que da influência das teorias pós-coloniais, que procedem à leitura dos fenómenos literários nascidos no seguimento dos movimentos de independência africanos iniciados na década de 50 do século XX, como movimentos de rutura com as literaturas das potências coloniais e a instituição de uma "tendência de autonomia por intermédio de algumas dominantes temáticas, tendentes a recuperar elementos históricos forjadores das novas identidades" (Mendonça, 2010, s/p).

De acordo com esta autora, o processo de construção de uma identidade e uma literatura nacional faz-se com e contra a herança e a memória colonial, revisitando, recriando e reescrevendo um imaginário que, por força das textualizações ${ }^{75}$ sucessivas, se vai tornando cada vez mais específico e individual.

A emergência da literatura timorense realizou-se, sobretudo numa primeira fase, pela via do texto lírico, sobretudo associado à intervenção, inicialmente de denúncia da situação colonial e depois de resistência face à invasão e ocupação estrangeira, percorrendo um caminho em tudo semelhante, apesar das especificidades, às demais literaturas nacionais dos países africanos de língua oficial portuguesa (Gonçalves, 2010, s/p). Neste domínio, merece especial destaque, pelo reconhecimento e maturidade, a obra de Fernando Sylvan, a que se seguiram produções desiguais, em termos de qualidade literária, de outros nomes relevantes, como Jorge Barros Duarte, Francisco Borja da Costa, Jorge Lauten, Celso Oliveira, Xanana Gusmão, João Aparício e Abé Barreto Soares, entre outros. Quase todos estão representados na coletânea Enterrem meu coração no Ramelau (1982), publicada em Luanda pela União de Escritores Angolanos (UEA). Claramente dominado pelas ideias de resistência face ao invasor, o volume em questão tem o condão de juntar autores de diferentes tendências e orientações políticas, assim como dar voz a alguns dos mais notáveis

\footnotetext{
${ }^{75}$ Confrontar com "Este conceito adquire um significado mais amplo, quando associado aos de transculturação e de transtextualidade, porque possibilita a leitura do córpus literário produzido por/contra os sistemas literários trazidos pela colonização, como transformações e apropriações das suas formas, com utilização de estratégias específicas que assim respondem à necessidade de forjar novos sistemas." (Mendonça, 2010, s/p).
}

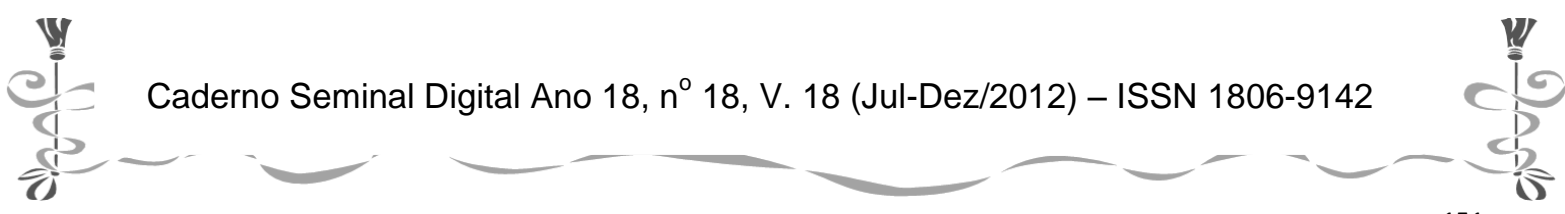




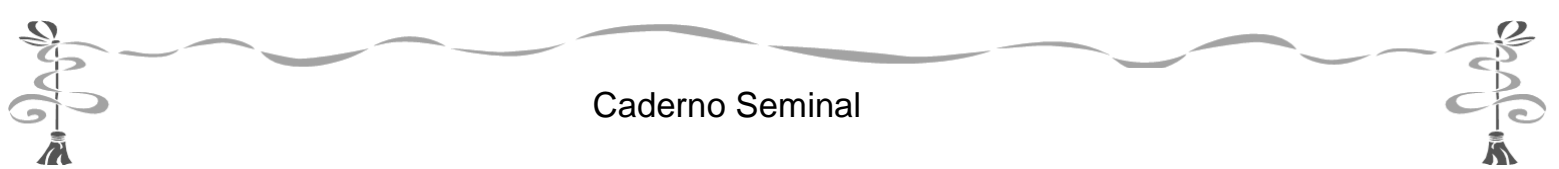

poetas timorenses da altura, com especial destaque para Fernando Sylvan ${ }^{76}$, Xanana Gusmão e, sobretudo, Jorge Lauten, pseudónimo cuja identidade real se mantém, até hoje, desconhecida.

Os textos deste último autor aqui publicados, incluindo o que empresta ao volume, destacam-se pela criação de um conjunto de sugestões emotivas muito fortes, quase todas evocando o sofrimento por uma pátria ocupada e ferida. A dor da ausência, em resultado do exílio em Portugal, combina-se com a saudade e o desespero de saber que, lá longe, há infelicidade. Fortemente metafórica, a sua poesia é a que melhor consegue superar os constrangimentos contextuais, abrindo possibilidades de leitura que ultrapassam o elogio dos valores de resistência e os desejos de liberdade, não ficando circunscrita - apesar das alusões referenciais - a uma leitura puramente contextual.

Introduzida por um prefácio que sublinha as circunstâncias políticas da edição, a antologia não deixa de ser apresentar como uma "amostra real no campo da poesia \{timorense\} escrita em língua portuguesa” (UEA, 1982, s/p), sublinhando que se trata de "poesia de combate" e que corresponde apenas a uma parte da produção existente, uma vez que a produção em tétum não se encontra representada.

Já João Aparício afirmou-se posteriormente através da edições de dois volumes ${ }^{77}$ de poesia publicados em Portugal sob a prestigiada chancela da Caminho (coleção Caminho da Poesia): À Janela de Timor (1999) e Uma Casa e Duas V acas (2000). Nos dois volumes em apreço, os seus textos tematizam universos ligados à história de Timor-Leste, recriando alguns dos acontecimentos mais relevantes das últimas décadas, com especial atenção para os anos da ocupação indonésia. A exaltação do espírito e da ação de resistência, assim como alguns dos seus principais mentores, são eixos centrais de muitos textos percorridos igualmente pelos motivos do sofrimento e da dor de um povo que, apesar do isolamento, nunca se deixou subjugar. Assim, é possível encontrar textos que quase escrevem a crónica dos dias da ocupação, registando - e denunciando - a violência, os massacres, as injustiças, mas cantando também os combates e as pequenas vitórias, testemunhos da esperança na singular coragem dos timorenses.

A narrativa de ficção ${ }^{78}$ é de afirmação mais tardia mas, curiosamente, e apesar de muito circunscrita à figura de Luís Cardoso, é, seguramente a que conheceu maior

\footnotetext{
${ }^{76}$ Sobre a obra de Fernando Sylvan, em particular sobre dois eixos ideotemáticos centrais - a resistência política e a dimensão amorosa - aguardamos a publicação de um estudo mais aprofundado que dedicámos ao autor de Tempo Teimoso. Com o objetivo de ter acesso à sua particular poética, aconselha-se a leitura de um volume que integra parte muito significativa da sua produção literária (Sylvan, 1993).

77 O poeta, que nasceu em Díli, em 1968, é também autor, sob pseudónimo de Kay Shaly Rakmabean, de Versos do Oprimido, acessível em http://amrtimor.org/docs/visualizador.php?bd=Documentos\&nome_da_pasta=06467.200\&numero_da_pagina=1

${ }^{78}$ Precedida, quase sempre, pela valorização, através de recolhas, dos textos da tradição oral, ainda com objetivos de legitimação, através da fixação, de uma cultura oral, assente na memória, que se quer reabilitar e dignificar, concedendo-lhe voz e espaço de manifestação e intervenção. E se, numa primeira fase, a questão da fidedignidade das fontes é ainda crucial, lentamente os temas,

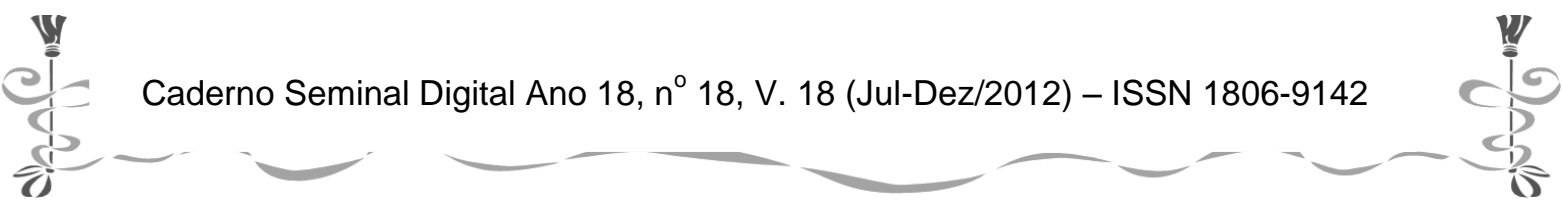




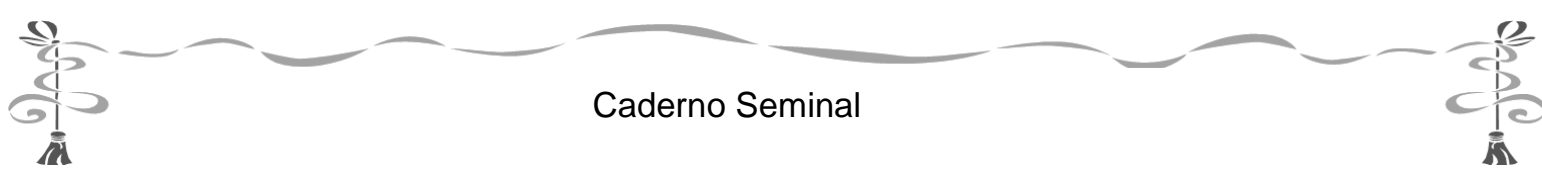

divulgação e reconhecimento, também por via das traduções ${ }^{79}$ e dos estudos ${ }^{80}$ de que tem sido alvo, e também do Prémio, em 1998, da Sociedade da Língua Portuguesa.

No universo ficcional timorense, a obra deste romancista é, possivelmente, aquela que revela essa construção gradual de um imaginário particular, em diálogo com múltiplas heranças cruzadas, questionadas e reescritas. Os seus quatro romances, para além das crónicas e contos dispersos, revelam um percurso sustentado de problematização de questões de identidade (nacional, cultural, linguística, religiosa...), situando-se geográfica e culturalmente no espaço timorense, passado e presente, mas estabelecendo pontes com outras realidades próximas e distantes. A descoberta da identidade pessoal cruza-se, no romance inaugural do autor, Crónica de uma travessia - A Época do Ai-Dik-Funam (1997), com o percurso e a deriva do próprio território timorense, um espaço náufrago e deambulante, construído nas próprias hesitações da História. Em todos os romances ${ }^{81}$ de Luís Cardoso é visível o destaque concedido ao contexto timorense, sobretudo em termos físicos, com a paisagem, a peculiar geografia, a fauna e a flora e os indivíduos, e também simbólicos, como acontece com as múltiplas línguas e culturas, incluindo tradições, imaginários e mitos), convergindo num exíguo espaço onde se manifestam múltiplas e multifacetadas identidades, a que se juntam miscigenações várias. A perspetiva narrativa, muito pessoal, também ela em processo gradual de construção e de afirmação, sublinha as singularidades locais e individuais, mas também procede ao seu reenquadramento e questionamento em termos globais e universais.

No caso do primeiro romance do escritor, Crónica de uma travessia. A época do Ai-DikFunam (1997), assistimos ao cruzamento de uma linha narrativa de índole referencial, com referências concretas a factos e a figuras conhecidas, com outra de cariz autobiográfico em registo memorialista. É desta interseção que se constrói - ou se procura construir - uma imagem unificadora de Timor-Leste, dando conta da instabilidade e da transitoriedade que marca o território e, consequentemente, as suas gentes, vivendo uma insularidade particular. A memória e a identidade são, deste modo, os eixos coesivos de um romance onde as viagens, realizadas em múltiplas direções e com distintas finalidades, têm lugar de destaque, estruturando a

motivos, registos e símbolos da herança cultural tradicional vão infiltrando a literatura de autor, sendo alvo, de forma gradual, de um processo subjetivo de apropriação. A literatura timorense oferece exemplos significativos deste processo, nomeadamente ao nível da reescrita dos mitos e lendas cosmogónicos, pela mão de escritores como Fernando Sylvan, Luís Cardoso ou Xanana Gusmão cuja análise guardaremos para outro contexto.

${ }^{79}$ Nomeadamente em inglês, francês, sueco, italiano e alemão. A edição em tétum, contudo, continua, ao que sabemos, adiada.

${ }^{80}$ Atendendo a profusão de estudos já realizados e publicados sobre este autor e a sua obra, com particular incidência no seu romance inaugural, não é possível proceder, no estreito espaço deste estudo, à sua inventariação. Chamamos a atenção, contudo, para uma das primeiras leituras de que foi alvo em Portugal, por parte de Maria Alzira Seixo, no JL de 25 de fevereiro de 1998 , pela receção elogiosa que realiza a relevante investigadora.

${ }^{81}$ Crónica de uma travessia - A Época do Ai-Dik-Funam (1997), Olhos de Coruja, Olhos de Gato Bravo (2001), A Última Morte do Coronel Santiago (2003) e Requiem para o Navegador Solitário (2007).

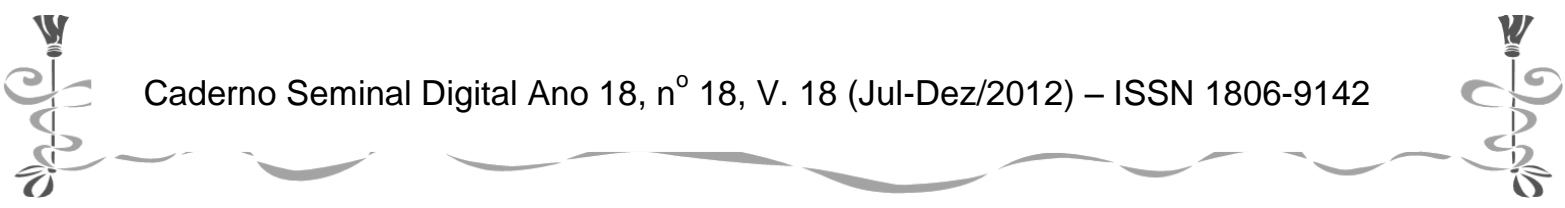




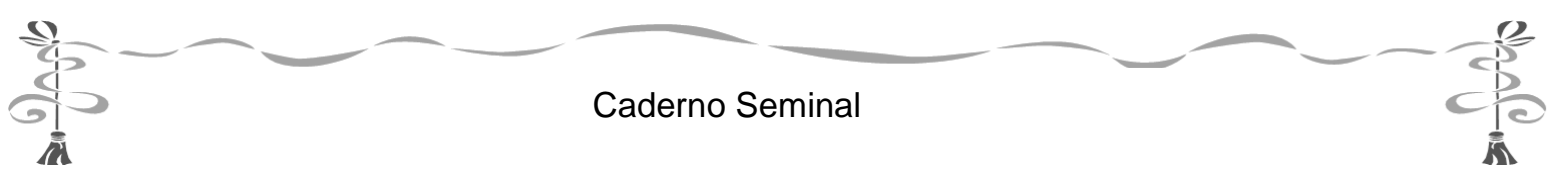

realidade e a própria organização temporal e espacial. É por isso que ao reescrever a sua história e a da sua família, em particular a do próprio pai, o narrador reflete sobre a história de Timor-Leste e sobre a forma como ela se confunde com a dos seus habitantes. As ocupações, as invasões, as guerras, a independência, os exílios e a diáspora ajudam a construir uma espécie de identidade precária que, um pouco à semelhança das vagas memórias do velho enfermeiro, corre risco de se perder enquanto deambula ao sabor de incontroláveis ventos e marés da História. A sua morte em Portugal, no final do romance, impossibilitando o regresso a casa, pode ser lida enquanto requiem pela perda de Timor e pelas suas parcas hipóteses de sobrevivência, mas, também, enquanto esperança renovada numa primavera redentora, de que a cena final é simbolicamente metafórica.

O último romance, Requiem para o Navegador Solitário, publicado dez anos depois do primeiro, volta a cruzar as linhas estruturantes da obra de Luís Cardoso, em particular a questão da identidade, entendida em termos individuais e nacionais, e da História, ficcionalmente recriada como uma espécie de mola que faz movimentar os homens, balizando as suas ações.

Protagonizada por Catarina, uma jovem chinesa iludida por sonhos de príncipes encantados e histórias de amores felizes, que se desloca para Timor onde espera reunir-se ao seu noivo, a narrativa dará conta do processo de crescimento e de amadurecimento da personagem, feito à custa de desilusões, desgostos, injustiças e muito sofrimento, uma espécie de metáfora da história do próprio território que simultaneamente a acolhe e renega.

Apanhada numa encruzilhada histórica particularmente difícil, mesmo antes do início da $2^{\mathrm{a}}$ Guerra Mundial, a protagonista e o território timorense, que com ela se confunde, parecem sofrer as violentas ondas de choque de todos os conflitos latentes num mundo cuja ordem e equilíbrio se revelam precários.

A rejeição do noivo seguida da sua violação física abrem as portas para uma sucessão de pequenas tragédias pessoais que a obrigam a crescer muito rapidamente, destruindo-lhe os sonhos infantis e a inocência, mas também a submeter-se a vários homens para sobreviver. $\mathrm{O}$ rapto do filho, a ostracização da comunidade e a perseguição dos habitantes locais destroem-lhe todas as ilusões e obrigam-na a viver numa nova realidade e a construir uma nova identidade. Mesmo o aparecimento do navegador solitário, Alain Gerbault, cujo livro a acompanhara desde a casa da família, uma espécie de derradeira esperança de felicidade pela qual aguardara desde a chegada a Timor, depressa se desvanece com a morte deste. A ocupação japonesa e os difíceis anos da guerra vividos num território aparentemente neutral marcarão indelevelmente a personagem, conduzindo-a a uma espécie de autoexílio voluntário no barco do navegador.

A partilhar o protagonismo (e o fascínio que a caracteriza) com Catarina está o próprio território timorense. Complexo e contraditório, personificando várias

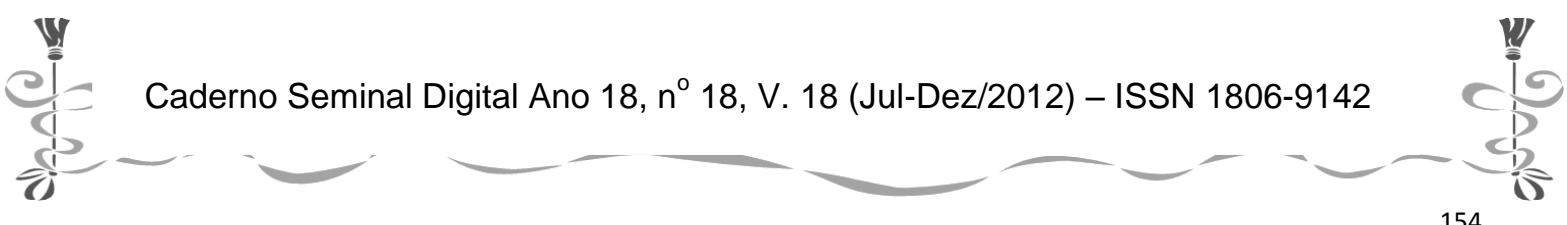




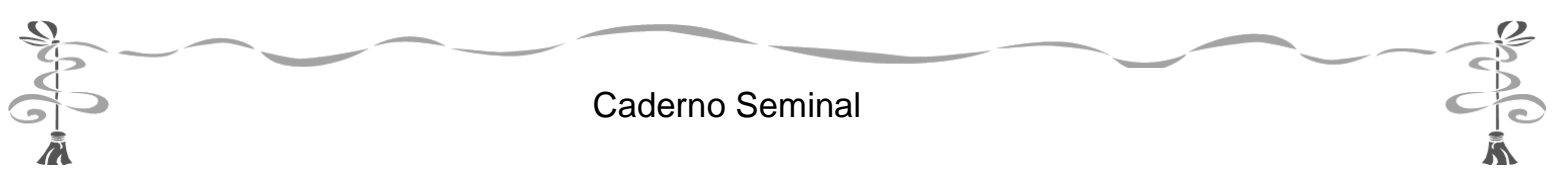

tensões internas e sofrendo consequências das pressões externas, Timor parece uma embarcação oscilando ao sabor das marés, ora perseguindo os habitantes nativos, ora se revoltando sucessivamente contra as vagas de ocupadores. Recriado ficcionalmente como uma espécie de território à deriva, Timor parece determinado numa demanda difícil pela sua afirmação. Violentado sucessivamente por diferentes invasores, assemelha-se a Catarina pela forma como parece manter uma dignidade original, reconstruindo-se sucessivamente, adoptando novas facetas e alguns disfarces, construindo uma identidade frágil, destinada à sobrevivência mais imediata.

O motivo do duplo, de presença assídua no romance, é sintomático da centralidade da reflexão sobre a identidade, verdadeiro fio coesivo da história. Várias personagens surgem divididas ou assumem posições contraditórias, exprimindo uma dualidade aparentemente irresolúvel. É o caso do administrador Malisera e do sipaio Marcelo, duas faces da mesma moeda da resistência ao poder branco; de Catarina, a Grande..., e a Outra, a gata de jade que também conquista Alberto Sacramento Monteiro e os outros capitães do porto que vão passando pela sua vida; mas também de Catarina e Madalena, as duas mães dos filhos de Alberto, duas penélopes tecedoras de sonhos e colecionadoras de gatos que esperam marinheiros perdidos no mar; da própria figura do capitão do porto que se desdobra em várias personagens que, afinal, são variações da mesma; de Alain Gerbault, o navegador solitário do livro e da imaginação de Catarina e o seu fantasma doente que regressa para morrer em Díli; dos australianos e dos japoneses, facções rivais da guerra, ocupantes violentos do território e das gentes; de Diogo e Esperança, o filho roubado e a filha morta, símbolos do futuro incerto que espera o território timorense.

A opção de Catarina de abandonar o veleiro e o tesouro, única forma de escapar a Timor, ao passado e às consequências da guerra, em troca da ténue esperança de rever o filho, ficando cativa do território que a persegue e critica, revela bem a mudança operada no íntimo da personagem, uma vez aberta a caixa de Pandora e revelado o seu destino:

O destino de uma mulher é uma caixa de Pandora. Nunca se sabe o que tem dentro. A sorte pode ditar um príncipe encantado. Nem sempre o desejado. Apaixonar-se por um marinheiro pode ser uma aventura sem retorno, como quando se entra pelo mar, quando as tempestades recomendam que se fique em terra. Sujeita-se a ser largada ao primeiro toque de rebate. Depois deambula à espera de ser resgatada por um coração de manteiga. Que o têm também os marinheiros solitários, viajantes em busca de outros ares, caçadores de fortunas, olheiros de mundos mágicos, músicos à procura de novas sonoridades, místicos no encalço do maravilhoso, escritores de histórias trágico-marítimas e pintores de paraísos que se vão apagando com o tempo (Cardoso, 2007, p. 12-13).

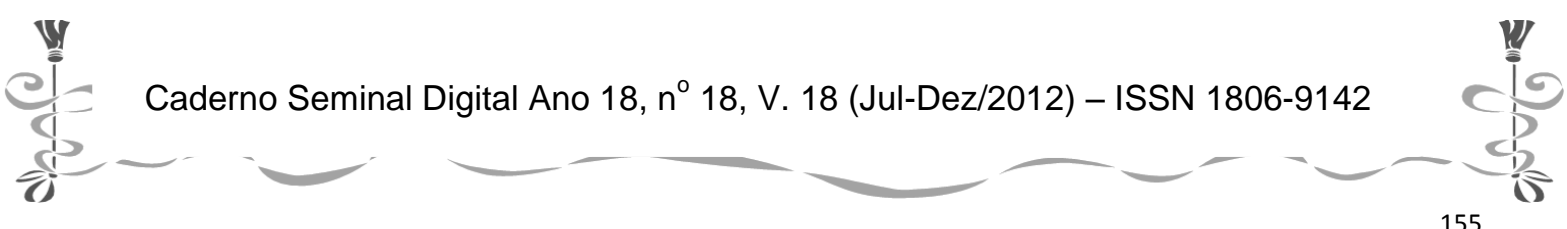




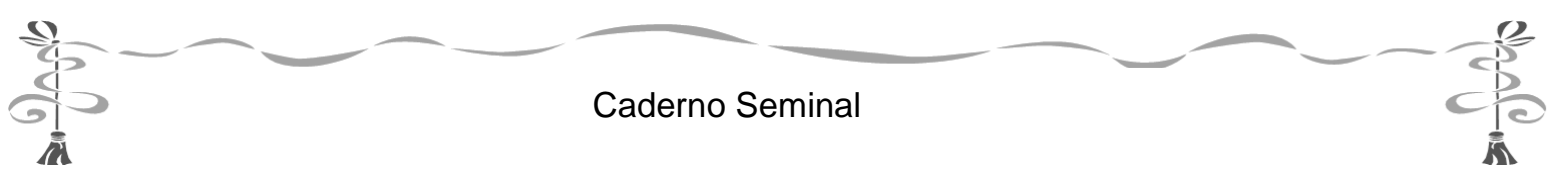

$\mathrm{Na}$ sua muito citada - também porque quase única - panorâmica da literatura timorense, João Paulo Esperança sistematiza, pelos modos lírico e narrativo, um conjunto de autores e de tendências que espelham bem o estado atual, mais em termos de produção do que de receção, da literatura produzida por autores oriundos daquele quadrante geográfico e cultural. As suas conclusões sublinham o facto de, no momento atual, a literatura timorense ser ainda, "com poucas exceções, fundamentalmente em língua portuguesa, veículo de afirmação de resistência, identidade e nacionalidade" (Esperança, 2005, p. 135), aguardando-se a produção em outras línguas locais, nomeadamente em tétum.

\section{Limitações e Constrangimentos para a Existência de uma Literatura Timorense}

Desde logo, a principal dificuldade para a divulgação e conhecimento da literatura e dos autores nacionais resulta da inexistência de uma produção editorial sediada em território timorense que inclua um circuito e uma rede de publicação, distribuição e venda. A falta de edição própria, estatal ou privada, leva a que todas as publicações se realizem fora do território nacional, nomeadamente em Portugal, dificultando o acesso aos livros e à leitura e, até, a formação de uma opinião pública informada e esclarecida. Catorze mil quilómetros de distância separam as publicações de Luís Cardoso ou João Aparício dos seus possíveis leitores, destinatários preferenciais dos livros.

As feiras do livro, entretanto realizadas e a abertura de um ou outro espaço exíguo de distribuição na capital provam o interesse pela leitura, mas sobretudo a necessidade de a divulgar de forma mais global e generalizada.

Para além disso, e em consequência de um longo período colonial a que se seguiram mais de duas décadas de ocupação e luta armada pela autodeterminação, culminando na destruição praticamente total das infraestruturas públicas, incluindo a aniquilação completa do sistema de ensino, o país, com dez anos de independência já marcados por uma ou outra convulsão social, debate-se com elevados níveis de analfabetismo e iliteracia, decorrentes de uma pobreza asfixiante que fazem com que os livros em geral e a literatura em particular sejam apenas propriedade das elites sociais e culturais, muitas delas constituídas por portugueses a residir no território, lusodescendentes, ou timorenses que fizeram formação no exterior. Para além disso, e apesar das decisões formalizadas em sede própria, há ainda, do ponto de vista social e cultural, questões de política linguística por resolver, adiando a estabilização do tétum e a implementação/consolidação do português.

A investigação sobre literatura timorense é, ainda, realizada de forma largamente maioritária fora do território nacional, sobretudo em Portugal e no Brasil, na área dos estudos literários e dos estudos comparados, mas também na Austrália e nos Estados-Unidos, em contextos ligados às literaturas emergentes, nomeadamente na linha dos estudos pós-coloniais ou dos estudos culturais.

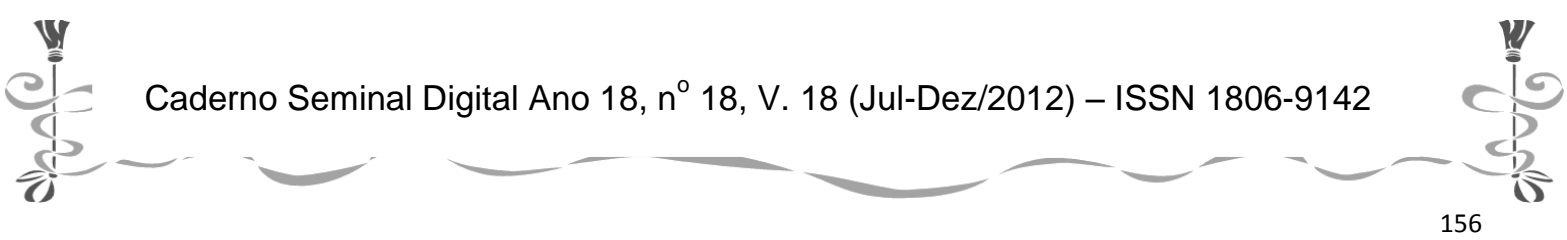




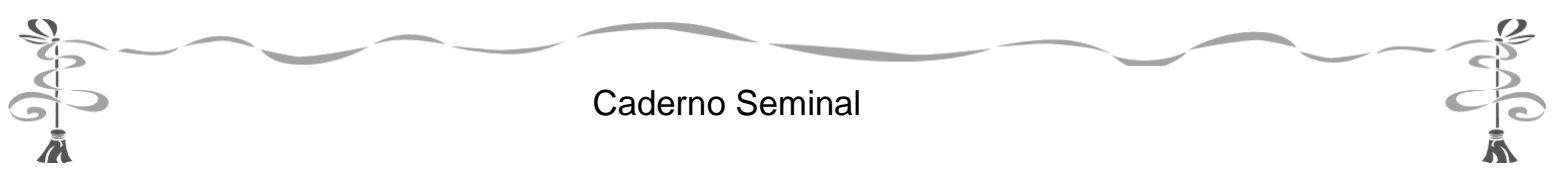

\section{Expectativas de Desenvolvimento e Legitimação}

Ainda que isolados e circunscritos a Díli e destinados a grupos de elite, como os alunos universitários, por exemplo, alguns movimentos têm procurado divulgar, no contexto timorense, a literatura nacional. $\mathrm{O}$ caso da Universidade Nacional de Timor Lorosae é, talvez, o mais relevante, sobretudo com a intervenção e o apoio do Instituto Camões e do Centro de Língua Portuguesa que desenvolvem, desde há mais de uma década, relevantes atividades de índole letiva e cultural. Assim, salientase a inclusão, no curso de formação de professores de língua portuguesa, de unidades curriculares na área da literatura timorense, contribuindo para a sua divulgação, estudo e ensino. Além disso, com relativa periocidade, manteve um jornal bilíngue, Várzea de Letras, responsável pela publicação de textos literários inéditos de novos autores e outros mais conhecidos, para além de estudos e de traduções de textos com vista à sua divulgação para além das fronteiras do universo académico. Mesmo se interrompida, a publicação deste jornal constitui ainda hoje, pela acessibilidade através de plataformas digitais, uma referência obrigatória para os estudos sobre autores atuais. Foi, igualmente, no contexto do Centro de Língua Portuguesa de Díli que surgiu a publicação de um volume literário coletivo, (Con)Textos, onde publicam, para além de alguns autores portugueses, professores a lecionar em Timor-Leste, um número significativo de timorenses, todos alunos, na sua maioria finalistas do curso referido anteriormente. Plataforma de lançamento e de divulgação de jovens talentos, o referido volume integra alguns textos que merecem atenção, como é o caso dos assinados por Danilio Barros ou Armandina Maia. Refira-se, aliás, que a proliferação de blogues, páginas pessoais e o relevo das redes sociais tem permitido a divulgação de textos, em diferentes línguas, sobretudo de autores jovens, a uma audiência alargada, fomentando o interesse e promovendo a leitura de textos de cariz diversificado.

Mas o passo mais relevante em termos de ensino resulta da implementação do projeto de Reestruturação do Ensino Secundário Geral timorense (2009-2012), apoiado pelo IPAD - Instituto Português de Apoio ao Desenvolvimento, pela Fundação Calouste Gulbenkian e pelo Fundo da Língua Portuguesa. Trata-se de um projeto realizado por uma vasta equipa coordenada pela Doutora Isabel P. Martins, sediado na Universidade de Aveiro, e que tem sido desenvolvido em estreita colaboração com o Ministério da Educação de Timor-Leste. Incluiu a elaboração de um Plano Curricular para o Ensino Secundário Geral e Programas, Manuais e Guias do Professor para as 14 disciplinas (e para os 3 anos de escolaridade) previstas, incluindo a nova disciplina de Temas de Literatura e Cultura ${ }^{82}$ que integra a componente das Ciências Sociais e Humanidades. Estruturada com vista a valorizar

\footnotetext{
${ }^{82}$ Coordenada pela autora deste texto, a equipa que desenvolve o trabalho de produção dos materiais pedagógicos para esta disciplina integra mais três elementos, dois professores universitários da área da literatura (Paulo Alexandre Pereira e Sara Reis da Silva) e uma professora do ensino secundário (Ana Paula Almeida), para além do contributo dos professores e interlocutores timorenses.
}

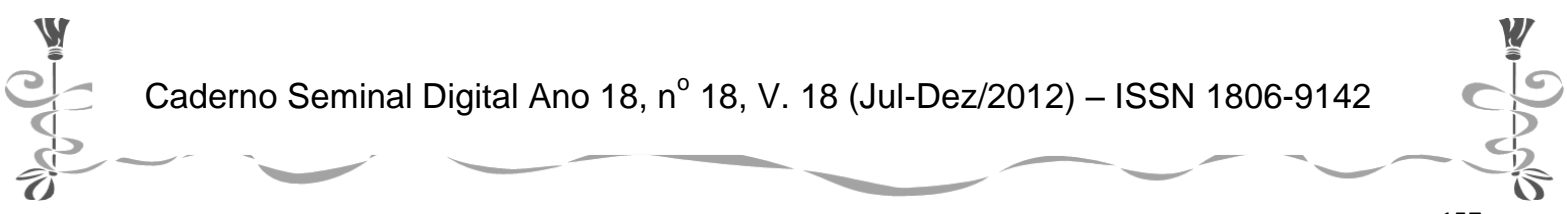




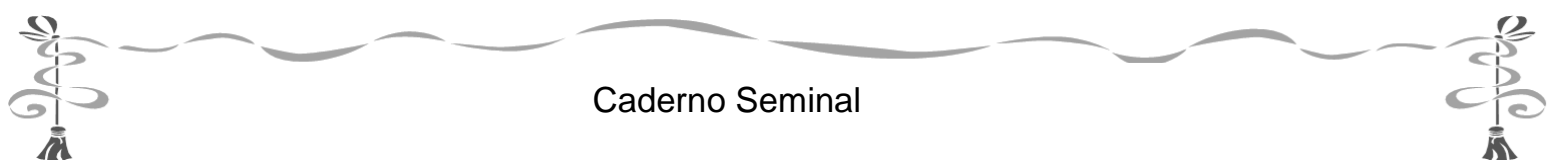

a literatura e cultura timorenses, promovendo a sua gradual legitimação e canonização através do estudo dos seus autores e respetivas obras literárias, esta disciplina não esquece a relevante relação com a lusofonia, fomentando o conhecimento das literaturas e culturas dos vários países de língua oficial portuguesa. Destaca o contexto contemporâneo e procura basear a seleção de textos, temas e conteúdos em universos de referência relevantes, próximos dos alunos e facilmente identificáveis. Apesar de não existir qualquer tradição no ensino secundário timorense de estudo do texto literário, a introdução desta nova disciplina revela-se pertinente para a construção da identidade nacional, tanto do ponto de vista cultural como social, colaborando na legitimação da literatura timorense, através da constituição de uma seleção de textos que, pelas suas qualidades e representatividade, são dignos de serem estudados como referências relevantes a par de textos oriundos de outros quadrantes da lusofonia. Os programas e manuais já elaborados preveem o estudo de alguns textos da literatura tradicional e das suas reescritas contemporâneas; da crónica literária e dos géneros intimistas, como o diário, as memórias, a carta ou a biografia; do texto poético, conto e romance; terminando com o estudo das relações interartísticas.

\section{Conclusões}

O estado atual de evolução da literatura timorense sugere que, durante os próximos anos, ela tenderá a legitimar-se, em resultado da ação combinada/articulada de vários fatores e movimentos, alguns externos ao fenómeno literário, como já procuramos dar conta. $\mathrm{O}$ aumento da regularidade editorial e a aproximação ao universo literário de novas vozes combinados com o estudo dos textos e a sua divulgação terão seguramente impacto a médio e a longo prazo, permitindo ultrapassar as dificuldades sentidas pelas primeiras edições oriundas do contexto timorense. Veja-se como, no caso de Luís Cardoso, Xanana Gusmão ou João Aparício, as respetivas primeiras obras, todas editadas em Portugal, foram introduzidas por prefácios que, além de apresentarem a obra e o autor, reivindicavam a legitimação de vozes literárias ainda não efetivamente reconhecidas. Respetivamente da responsabilidade José Eduardo Agualusa, Mia Couto e Sophia de Mello Breyner Andresen os prefácios sublinham a condição emergente da literatura a que pertencem os textos, mas também o seu pendor combativo e interventivo em defesa da liberdade, por ação do "resgate da memória" (Agualusa, 1997, p. 5), nas palavras de Agualusa. Para Sophia, o livro À Janela de Timor constitui uma manifestação "de revolta moral e intelectual perante o esmagamento de um povo" (Andresen, 1999, p. 13), enquanto Mia Couto, por seu turno, realça o facto de a poesia de Xanana reunida em Mar Meu "falar de um povo, uma nação. Há ali não apenas poesia mas uma epopeia de um povo, um heroísmo que queremos partilhar, uma utopia que queremos que seja nossa" (Couto, 1998, p. 6). Cumprindo a sua função de "projeção pública e propósito de pervivência cultural" (Reis, 1997, p. 216), os prefácios favorecem a institucionalização dos textos que acompanham e, no

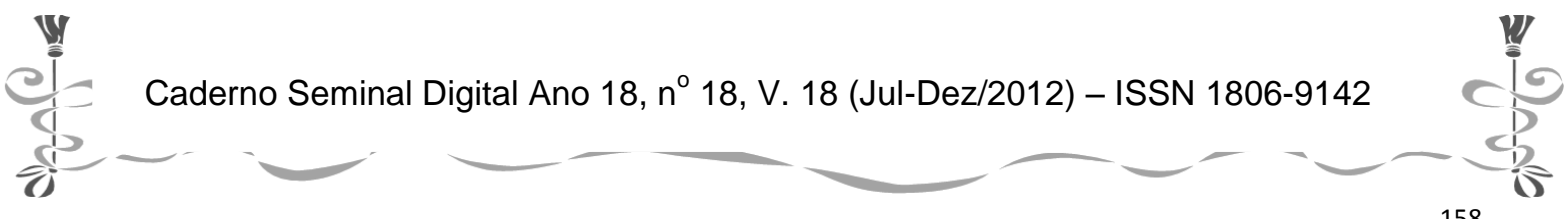




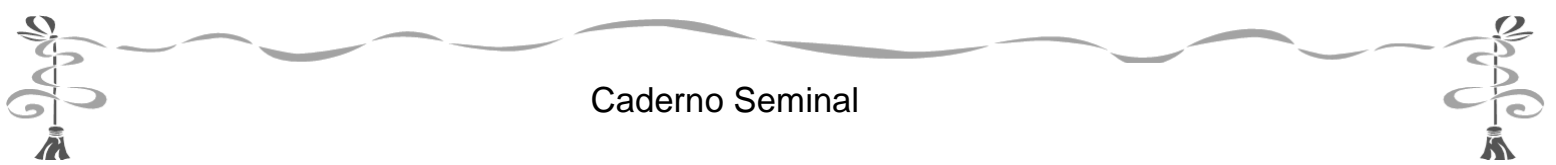

caso em análise, constituem elementos cruciais na legitimação e no enquadramento de toda uma literatura. Neste caso, são unânimes em sublinhar a vinculação da literatura timorense a um contexto e a uma missão relevantes, mas de alguma forma estranguladores em termos de autonomia estética e singularização.

No caso dos volumes posteriores, nomeadamente de Luís Cardoso e João Aparício que deram seguimento à produção literária, respetivamente no romance e na poesia, este reforço legitimador dos paratextos já não se justificou, evidenciando uma autonomização gradual dos percursos literários.

A recente instituição de um prémio literário batizado com o nome de Ruy Cinatti, uma iniciativa da Imprensa Nacional Casa da Moeda, permitiu a edição da obra distinguida por um júri presidido por Carlos Reis em 2010, Sou nada ou nada sou? (2012), de Cidália Cruz, lançada na Feira do Livro de Baucau com apresentação de Joana Ruas. Trata-se de um breve texto de índole intimista, entre o diário e a prosa poética, devedor da leitura de Clarice Lispector, e constitui um exercício introspetivo fragmentado, com o qual se cruzam as vivências do quotidiano, transformadas pela ação reflexiva de um sujeito poético/narrativo e processo de crescimento, autodescoberta e afirmação identitária. Esta jovem autora também já foi distinguida num outro concurso em língua tétum, promovido pela Timor Aid e a Fundação Alola, com a obra Katak Nonook. O Prémio Literário Ruy Cinatti, a que só podem concorrer cidadãos timorenses, tem como principal missão a descoberta de novos talentos literários, contribuindo para a sua divulgação através da edição dos seus livros.

A revista Ellipsis, da American Portuguese Studies Association, prepara neste momento um número especial dedicado a Timor-Leste, no âmbito das celebrações dos seus 10 anos de independência que trará, seguramente, novas luzes sobre a literatura daquele país.

Em crescente afirmação e divulgação, a literatura timorense tem realizado um percurso interessante, autonomizando-se em relação à referencialidade que, durante décadas, foi a sua exclusiva razão de ser. Sem deixar de ser interventiva e questionadora, problematizando, por exemplo, a relação com o passado, nomeadamente a presença colonial e a ocupação indonésia, tem-se sobretudo distinguido pela forma como revisita e recria uma herança tradicional muito rica e diversificada, procedendo à sua reactualização. A necessitar de divulgação, estudo atento e reconhecimento, a literatura timorense poderá seguir os passos cada vez mais seguros - e mais inovadores também - das suas irmãs africanas, nomeadamente a angolana e moçambicana.

\section{Referências}

AGUALUSA, José Eduardo. "Como se fosse um prefácio”, in CARDOSO, Luís. Crónica de uma travessia. A época do Ai-Dik-Funam. Lisboa: Publicações Dom Quixote, 1997, pp. 5-6.

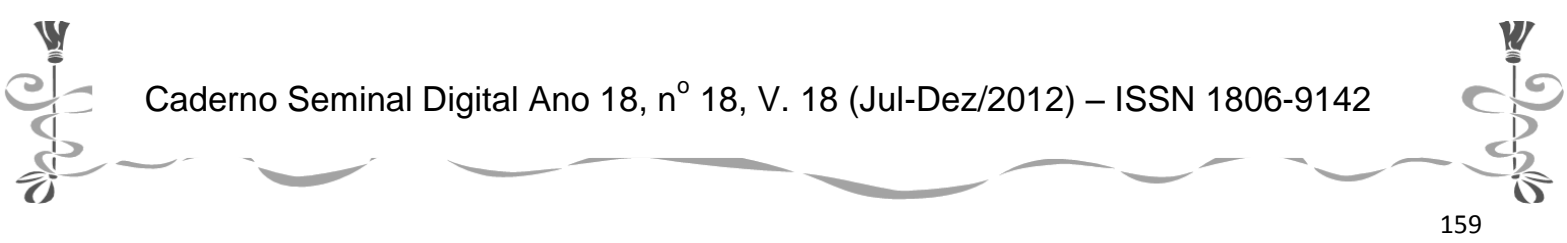




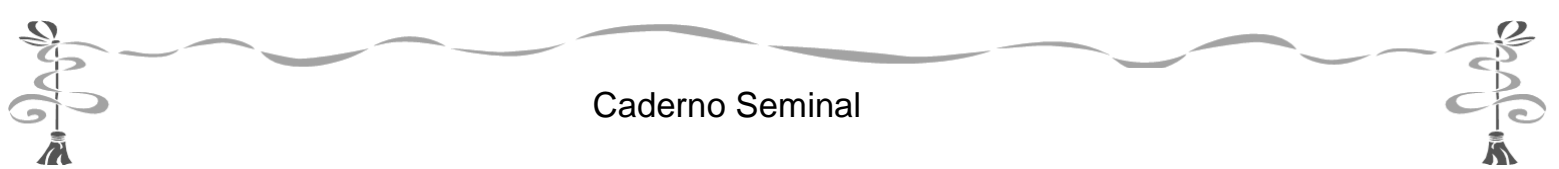

ANDRESEN, Sophia de Mello Breyner. "Prefácio", in APARÍCIO, João. À Janela de Timor. Lisboa: Caminho, 1999, pp. 11-17.

APARÍCIO, João. À janela de Timor. Lisboa: Caminho, 1999.

APARÍCIO, João. Uma Casa e Duas Vacas. Lisboa: Caminho, 2000.

CARDOSO, Luís. Crónica de uma travessia. A época do Ai-Dik-Funam. Lisboa: Publicações Dom Quixote, 1997.

CARDOSO, Luís. Requiem para o Navegador Solitário. Lisboa: Publicações Dom Quixote, 2007.

COUTO, Mia. "Prefácio. O Verso e o Universo / Preface. Verse and Universe", in GUSMÃO, Xanana. Mar Meu. Poemas e Pinturas/ My Sea of Timor. Poems and Paintings. Porto: Granito/Instituto Camões, 1998, pp. 6-9.

CRUZ, Cidália. Sou nada ou nada sou? Lisboa: Imprensa Nacional Casa da Moeda, 2012.

DUARTE, João Ferreira, "Cânone" in E-Dicionário de Termos Literários (org. de Carlos Ceia), sem data bttp: / / www.fcsh.unl.pt/ edtl/verbetes/C/canone.htm

GONÇALVES, Zetho Cunha. "Prefácio a uma Antologia do Conto Africano" in Buala. Cultura Contemporânea Africana, 2010 http: //www.buala.org/pt/a-ler/prefacio-a-umaantologia-do-conto-angolano

MENDONÇA, Fátima. "Literaturas emergentes, identidades e cânone" in Buala. Cultura Contemporânea Africana, 2010 http://www.buala.org/pt/a-ler/literaturas-emergentesidentidades-e-canone

REIS, Carlos. O Conhecimento da Literatura. Introdução aos Estudos Literários. Coimbra: Almedina, 1997.

SYLVAN, Fernando. A Voz Fagueira de Oan Tímor. Lisboa: Edições Colibri, 1993.

UNIÃO DOS ESCRITORES ANGOLANOS. Enterrem meu coração no Ramelau - Poesia de Timor-Leste. Luanda: União dos Escritores Angolanos, 1982.

Caderno Seminal Digital Ano 18, nº 18, V. 18 (Jul-Dez/2012) - ISSN 1806-9142

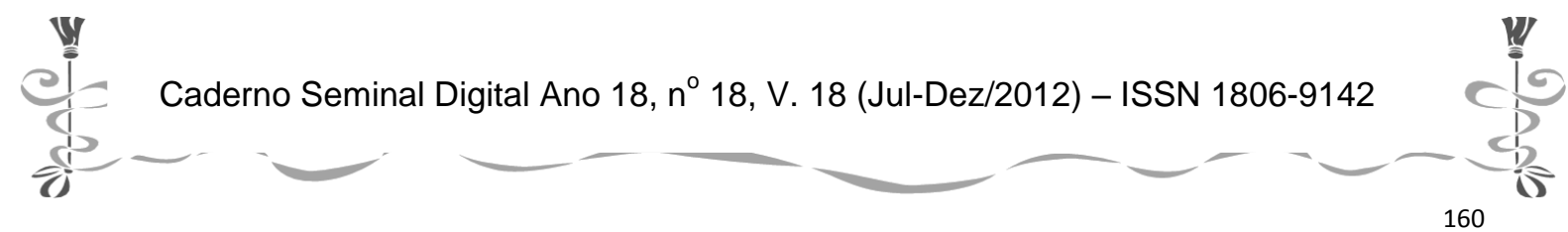

